\section{Brustimplantate: Kapselkontraktur durch Biofilme?}

\section{Kapsuläre Kontrakturen sind häufige Komplikationen, aufgrund deren ein Brustimplantat oft wieder entfernt werden muss. Nach einer aktuellen Studie liegt die Ursache für die Probleme in einem Bakterienfilm auf den Implantaten, der eine Fibrosereaktion induziert.}

$\mathrm{N}$ ach einigen Studien treten Kapselkontrakturen mit einer Häufigkeit von $50-74 \%$ auf. Die genaue Ursache für diese Komplikation ist bisher unklar. Als Auslöser werden Fremdkörperreaktion, Hämatome sowie eine periimplantäre Infektion vermutet. Neuere Daten lassen vermuten, dass möglicherweise subklinische Infektionen oder Biofilme eine Rolle bei dieser Komplikation spielen. Der spezifische Nachweis von Bakterien auf Implantaten war bisher jedoch schwierig und eine Abgrenzung zwischen unproblematischen Biofilmen und einer Kontamination nicht immer sicher möglich.

In der vorliegenden Studie wurde nun ein Verfahren vorgestellt, durch das Keime aus Biofilmen von Brustimplantaten herausgelöst werden können. An der US-amerikanischen Mayo-Klinik untersuchten Kollegen 45 Brustimplantate, die aus verschiedensten Gründen (nur ein Fall einer offensichtlichen In- fektion) entnommen wurden. Das Entfernen der Biofilme erfolgte mittels einer Vortex-/Ultraschallbehandlung, die Flüssigkeit mit den abgelösten Keimen (Sonikat) wurde bakteriologisch untersucht.

27 der 45 Brustimplantate wurden wegen einer erheblichen kapsulären Kontraktur entnommen. Von diesen 27 Brust-

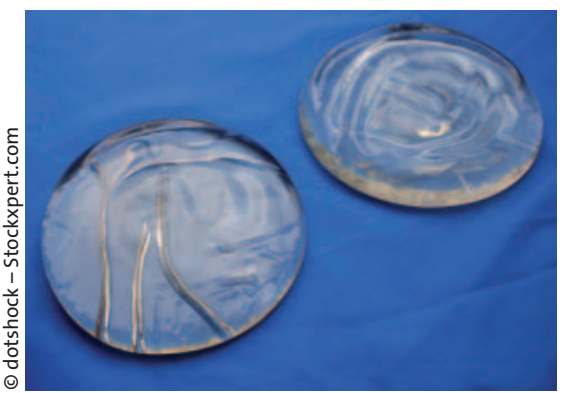

Brustimplantate bieten Bakterien einen hervorragenden Nährboden - dies scheint auch ein Grund für das Auftreten von Kapselkontrakturen zu sein. implantaten wiesen 9 (33\%) eine Bakterienzahl von mindestens 20 koloniebildenden Einheiten $/ 10 \mathrm{ml}$ Sonikat auf. Von den 18 Implantaten, die aus anderen Gründen entfernt wurden, fand sich nur bei einem (5\%) eine Bakterienzahl von $\geq 20$ koloniebildenden Einheiten $/ 10 \mathrm{ml}$ Sonikat $(p=0,034)$. Aus den Sonikaten ließen sich Propionibacterium-Spezies, Koagulase-negative Staphylokokken und Corynebakterien anzüchten. Die Autoren folgern aus diesen Ergebnissen, dass Bakterien im Biofilm des Implantates mit den kapsulären Kontrakturen assoziiert sind.

Kommentar: Es handelt sich zwar hier um eine Pilotstudie mit niedrigen Fallzahlen, jedoch weisen die Ergebnisse in eine eindeutige Richtung: Wie bei anderen künstlichen Materialien kann es zur Ausbildung eines Biofilms auf der Oberfläche des Brustimplantats kommen, der dann Bakterien - meist Hautkeimen - einen hervorragenden Nährboden bietet. Hierdurch wird eine Abwehrreaktion des Körpers induziert, die dann zur kapsulären Kontraktur führt.

T. F. Schwarz

Del Pozo JL et al. Pilot study of association of bacteria on breast implants with capsular contracture. J Clin Microbiol 2009; 47: 1333-7.

\section{Der Paracetamolfuß}

— Eine 22-jährige Schwangere nahm beim Eintreten der Wehen zwei Tabletten Paracetamol ein. Nach der problemlosen Geburt während der Nacht bemerkte sie am nächsten Morgen einen brennenden kirschroten Fleck am linken Fußrücken. Im weiteren Verlauf verfärbte sich der Fleck fast schwarz im Sinne einer postinflammatorischen Pigmentierung.

Die Patientin ließ sich nicht davon abbringen, dass diese Hauterscheinung durch Paracetamol hervorgerufen worden sei. Tatsächlich stellte sie sich sechs Wochen später mit dem gleichen Problem vor, das dieses Mal nach der Einnahme von einer Tablette Paracetamol aufgetreten war.
Auch bei dieser Gelegenheit veränderte sich die Hauterscheinung von rot auf dunkelbraun. Bei der Patientin wurde die Diagnose eines fixen Arzneimittelexanthems gestellt.

Diese Exantheme sind üblicherweise solitär. Sofern mehrere Läsionen auftreten, wird eine Reexposition nicht empfohlen. Die dunklen Flecken gehen im Lauf von Monaten oder Jahren von allein zurück, sofern das angeschuldigte Medikament vermieden wird.

H. S. FüeßI

Quartey-Papafio C.

Brit Med J 2009; 339: 56.

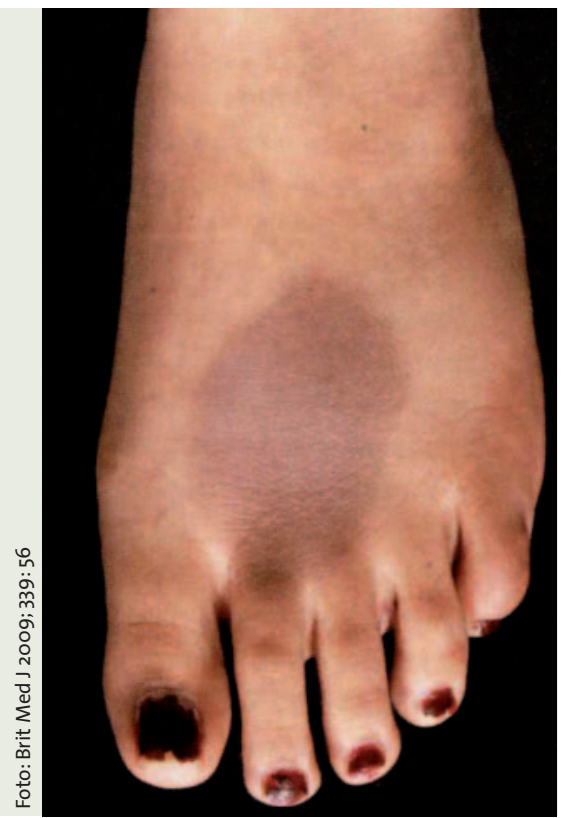

